\title{
On the working of the mindsponge concept and the bayesv/ R package
}

\author{
Minh-Hoang Nguyen \\ Manh-Toan Ho $(*)$ \\ Tam-Tri Le \\ Huyen T. T. Nguyen \\ Hong-Kong T. Nguyen
}

AISDL \& SDAG Key Research Lab

Phenikaa University

Yen Nghia, Ha Dong District, Hanoi 100803, Vietnam

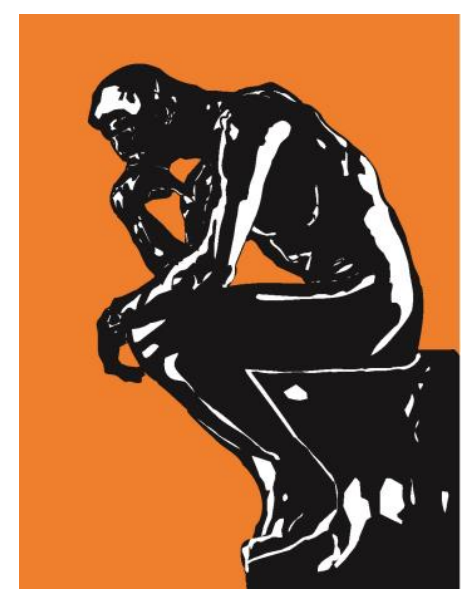

February 14, 2021

(*) Correspondence: Manh-Toan Ho; toan.homanh@phenikaa-uni.edu.vn

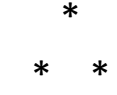

Our AISDL research team has used the concept of "mindsponge" extensively, in numerous research studies, since 2018. The concept was first introduced by Vuong (2016) and Vuong \& Napier (2015). Nonetheless, it has become increasingly applicable since empirical studies and 
further conceptual developments and real-world applications such as Nguyen et al. (2019), Nguyen, Le \& Meirmanov (2019).

Before our extensive use of the theory, it had already received support from other conceptual applications and developments, which help us better understand (and benefit from) its values and relevance and further calibrate our subsequent studies, both conceptually and empirically.

Those publications that shed light on its use and potential include Donato (2019), Ranizal et al. (2019), Verrips \& Schoonewelle (2019), Basinsk \& Rozkwitalska (2020), Bărbulescu, Tecău, Munteanu \& Constantin (2021), Stoermer, Laurin, \& Selmer (2020), Fischer (2021), Kowalski \& Rybacki (2021), to name just a few. The applications range from psychology to business administration and innovation processes to mental health studies.

Nonetheless, our subsequent studies have greatly benefited from a data science weapon, the bayesvl R package, also developed by the main author of the mindsponge concept and our colleague (La \& Vuong, 2019; Vuong et al., 2020b; Vuong et al., 2020c).

The Bayesian network data analytical method, employing the computing power equipped by the Hamiltonian MCMC technique, has enabled us to investigate much more deeply into complex issues - that the mindsponge processes might require us to-and explore the possible causal nexus thereof. Thanks to the power of the bayesvl package, the mindsponge concept has helped to shed light on several important socio-cultural phenomena through such publications as Vuong et al. (2018), Vuong et al. (2020a), Vuong (2021), and Vuong et al. (2021).

The usefulness of the mindsponge notion has been aided by the philosophical reasoning nature inherent in the Bayesian belief updating process. For this exact reason, we have been able to develop further research models capable of investigating increasingly complex socio-cultural and psychological problems. It is also noteworthy, drawn upon our actual research experience, that the mindsponge concept and Bayesian updating notion can work together quite well in research problems that do not require Bayesian computing at all.

\section{References}

Bărbulescu, O., Tecău, A. S., Munteanu, D., \& Constantin, C. P. (2021). Innovation of Startups, the Key to Unlocking Post-Crisis Sustainable Growth in Romanian Entrepreneurial Ecosystem. Sustainability, 13(2), 671.

Basinska, B. A., \& Rozkwitalska, M. (2020). Psychological capital and happiness at work: The mediating role of employee thriving in multinational corporations. Current Psychology, 1-14. 
Donato, R. A. (2019). Global Mindset Strategies for Increasing Hotels' Performance. Walden University Doctoral Dissertation.

Fischer, T. (2021). Understanding the Spatial-Related Abstraction of Public Health Impact Goals and Measures: Illustrated by the Example of the Austrian Action Plan on Women's Health. Sustainability, 13(2), 773.

Kowalski, A. M., \& Rybacki, J. (2021). Moderate Innovator Trap-Does the Convergence of Innovation Performance Occur in the World Economy?. Economies, 9(1), 11.

La, V. P., \& Vuong, Q. H. (2019). bayesvl: Visually learning the graphical structure of Bayesian networks and performing MCMC with 'Stan'. The Comprehensive R Archive Network (CRAN).

Mohd Ranizal, M. A., Wan Zabidi, W. Q., Mohd Shariff, S. A., Stanis, J., \& Shamsul Amir, S. A. (2019). Depression among university students. e-Journal of Media \& Society, 2, 1-15.

Nguyen, M. H., Le, T. T., \& Meirmanov, S. (2019). Depression, acculturative stress, and social connectedness among international university students in Japan: a statistical investigation. Sustainability, 11(3), 878.

Nguyen, H. K. T., Nguyen, V. H. T., Vuong, T. T., Ho, M. T., \& Vuong, Q. H. (2019). The new politics of debt in the transition economy of Vietnam. Austrian Journal of South-East Asian Studies, 12(1), 91-110.

Stoermer, S., Lauring, J., \& Selmer, J. (2020). The effects of positive affectivity on expatriate creativity and perceived performance: What is the role of perceived cultural novelty?. International Journal of Intercultural Relations, 79, 155-164.

Verrips, A., \& Schoonewelle, L. (2019). The employee's journey to a new organisational culture. Lund University Master's Thesis.

Vuong, Q. H. (2021). The semiconducting principle of monetary and environmental values exchange. Economics and Business Letters, 10(3), 1-9.

Vuong, Q. H., et al. (2018). Cultural additivity: behavioural insights from the interaction of Confucianism, Buddhism and Taoism in folktales. Palgrave Communications, 4(1), 143.

Vuong, Q. H., et al. (2020a). On how religions could accidentally incite lies and violence: Folktales as a cultural transmitter. Palgrave Communications, 6(1), 82.

Vuong, Q. H., et al. (2020b). Improving Bayesian statistics understanding in the age of Big Data with the bayesvl R package. Software Impacts, 4, 100016.

Vuong, Q. H., et al. (2020c). Bayesian analysis for social data: A step-by-step protocol and interpretation. MethodsX, 7, 100924.

Vuong, Q. H., Ho, M. T., Nguyen, M. H., Pham, T. H., et al. (2021). On the environmentdestructive probabilistic trends: a perceptual and behavioral study on video game players. Technology in Society, 65, 101530. 